\title{
Performance Comparative Analysis of S-Glass Epoxy Composite Leaf Spring with Mild Steel Leaf Spring
}

\author{
T. Bhanuprasad ${ }^{1}$, A Purushotham $^{2}$ \\ 1-M.Tech (Cad/Cam) Student, Department of Mechanical Engineering, SreeNidhi Institute of Science \& \\ Technology: Hyderabad A.P., India \\ $2 \& 3$ Professor, Department of Mechanical Engineering, SreeNidhi Institute of Science \& Technology: \\ Hyderabad A.P., India.
}

\begin{abstract}
A leaf spring is a simple form of spring, commonly used for the suspension in wheeled vehicles. Leaf Springs are long and narrow plates attached to the frame of a trailer that rest above or below the trailer's axle. There are mono leaf springs, or single-leaf springs, that consist of simply one plate of spring steel. These are usually thick in the middle and taper out toward the end, and they don't typically offer too much strength and suspension for towed vehicles. Drivers looking to tow heavier loads typically use multi leaf springs, which consist of several leaf springs of varying length stacked on top of each other. The shorter the leaf spring, the closer to the bottom it will be, giving it the same semi elliptical shape a single leaf spring gets from being thicker in the middle. Presently leaf spring is made up with forged steel. In this paper, we designed leaf spring for the materials Mild Steel and composite material s-glass epoxy and compared their performance in terms of deflection, stress and vibration. We also checked the strength variations while changing layers. For validating this design, we conducted FEA Structural Analysis on both steel leaf spring and composite leaf spring.. Modal analysis is also done to compare vibration characteristics of steel and composite leaf springs
\end{abstract}

Keywords - semi elliptical, composites, leaf spring,

\section{INTRODUCTION}

Semi-elliptic leaf springs are almost universally used for suspension in light and heavy commercial vehicles. For cars also, these are widely used in rear suspension. The spring consists of a number of leaves called blades. The blades are varying in length. The blades are us usually given an initial curvature or cambered so that they will tend to straighten under the load. The leaf spring is based upon the theory of a beam of uniform strength. The lengthiest blade has eyes on its ends. This blade is called main or master leaf, the remaining blades are called graduated leaves. All the blades are bound together by means of steel straps. The spring is mounted on the axle of the vehicle. The entire vehicle load is rests on the leaf spring. The front end of the spring is connected to the frame with a simple pin joint, while the rear end of the spring is connected with a shackle. Shackle is the flexible link which connects between leaf spring rear eye and frame. When the vehicle comes across a projection on the road surface, the wheel moves up, this leads to deflecting the spring. This changes the length between the spring eyes. The steel structure leaf springs are definitely heavy mass. In order to reduce the weight an attempt is made in this paper $\mathrm{t}$ with $\mathrm{S}$-Glass Epoxy composites, which is almost 50times less weight than steal spring.

Pro/ENGINEER Wildfire is the standard in 3D product design, featuring industry-leading productivity tools that promote best practices in design while ensuring compliance with your industry and company standards. Integrated Pro/ENGINEER CAD/CAM/CAE solutions allow you to design faster than ever, while maximizing innovation and quality to ultimately create exceptional products. Customer requirements may change and time pressures may continue to mount, but your product design needs remain the same - regardless of your project's scope, you need the powerful, easy-to-use, affordable solution that Pro/ENGINEER provides.

\section{D DRAWING}

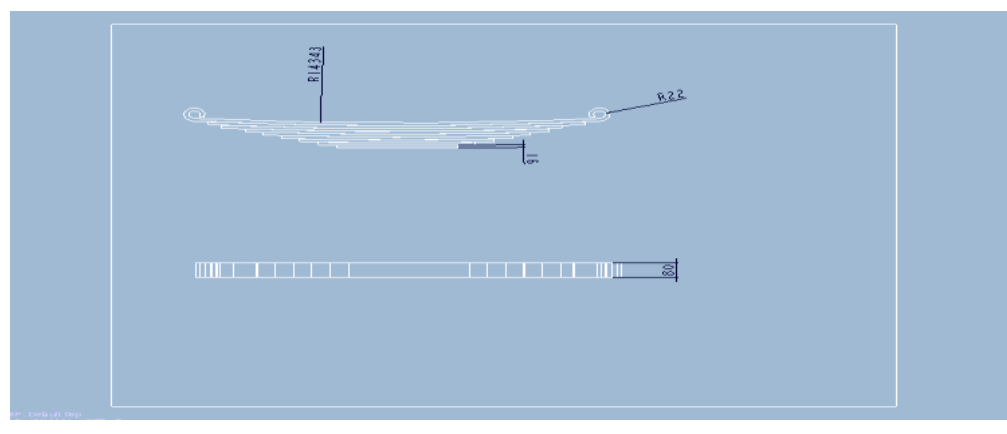




\subsection{INTRODUCTION TO ANSYS}

ANSYS is general-purpose finite element analysis (FEA) software package. Finite Element Analysis is a numerical method of deconstructing a complex system into very small pieces (of user-designated size) called elements. The software implements equations that govern the behaviour of these elements and solves them all; creating a comprehensive explanation of how the system acts as a whole. These results then can be presented in tabulated, or graphical forms. This type of analysis is typically used for the design and optimization of a system far too complex to analyze by hand. Systems that may fit into this category are too complex due to their geometry, scale, or governing equations.

\section{Variation Of Exciting Frequency With Vehicle Speed}

\begin{tabular}{|c|c|c|c|c|c|}
\hline $\begin{array}{c}\text { Speed } \\
\text { (Kmph) }\end{array}$ & $\begin{array}{c}\text { Frequency Hz (at } \\
\text { WRI=1m) }\end{array}$ & $\begin{array}{c}\text { Frequency Hz (at } \\
\text { WRI =2m) }\end{array}$ & $\begin{array}{c}\text { Frequency Hz (at } \\
\text { WRI =3m) }\end{array}$ & $\begin{array}{c}\text { Frequency Hz (at } \\
\text { WRI=4m) }\end{array}$ & $\begin{array}{c}\text { Frequency Hz (at } \\
\text { WRI =5m) }\end{array}$ \\
\hline 20 & 5.5500 & 2.77 & 1.8518 & 1.3888 & 1.11111 \\
\hline 40 & 11.1111 & 5.54 & 3.7037 & 2.7777 & 2.22222 \\
\hline 60 & 16.6666 & 8.31 & 5.5555 & 4.1664 & \\
\hline 80 & 22.2222 & 11.08 & 7.4074 & 5.5552 & \\
\hline 100 & 27.7777 & 13.85 & 9.2593 & 6.44444 & 6.9440 \\
\hline
\end{tabular}

Modal Calculation for excitation frequency:

$$
\begin{aligned}
& \text { Speed } \mathrm{v}=100 \mathrm{kmph} \quad=100 \times 5 / 18 \mathrm{~m} / \mathrm{sec}=500 / 18 \mathrm{~m} / \mathrm{sec} \\
& \text { WRI } \mathrm{L}=1 \mathrm{~m} \\
& \text { Excitation frequency }=2 \pi \times(500 / 18) / 1 \mathrm{rad} / \mathrm{sec} \\
& =[2 \pi \times(500 / 18) / 1] / 2 \pi \mathrm{Hz} \quad=27.7777 \mathrm{~Hz}
\end{aligned}
$$

III. Modelling Of Leaf Spring In Pro/E

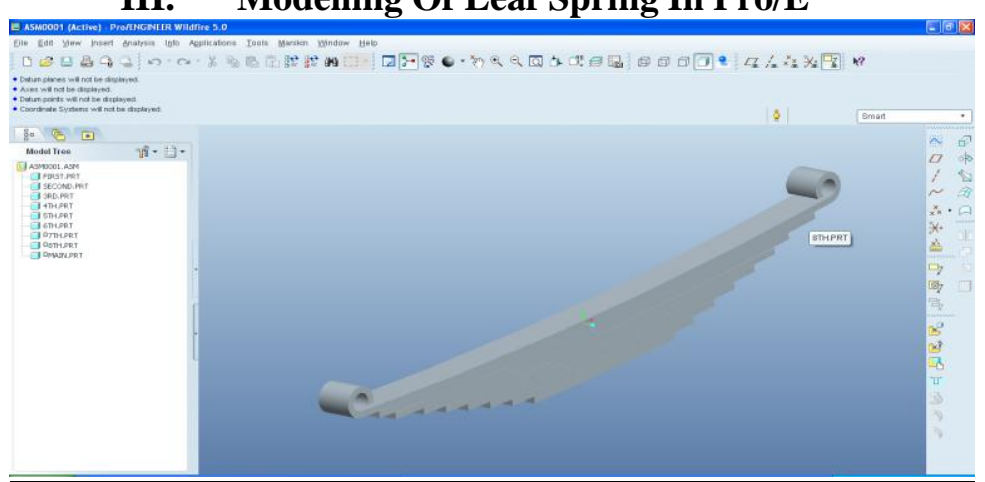

Fig 3.1 leaf spring designed in pro/e software

\section{STRUCTURAL}

\section{Specific Capabilities Of Ansys}

Structural analysis is probably is the most common application of the finite element method as it implies mechanical structures such as ship hulls, aircraft bodies and mechanical housing as well as mechanical components such as piston, machine parts and tools.

\section{Static analysis}

Used to determine displacements, stress...etc. under static loading conditions. ANSYS can compute both linear and non-linear static analyses, non-linearity's can include plasticity stress stiffening, large deflection, large strain, hyper elasticity, contact surfaces and creep

\section{Modal Analysis}

A modal analysis is typically used to determine the vibration characteristics (natural frequencies and mode shapes) of a structure or a machine component while it is being designed. It can also serve as a starting point for another, more detailed, dynamic analysis, such as a harmonic response or full transient dynamic analysis.

Modal analyses, while being one of the most basic dynamic analysis types available in ANSYS, can also be more computationally time consuming than a typical static analysis. A reduced solver, utilizing automatically or manually selected master degrees of freedom is used to drastically reduce the problem size and solution time. 
MILD STEEL

\section{Analysis Of Leaf Spring}

Element Type: Solid 20 node 95

Material Properties: Youngs Modulus (EX) : 205000N/mm²

Poissons Ratio (PRXY) : 0.29

Density $\quad: 0.000007850 \mathrm{~kg} / \mathrm{mm}^{3}$
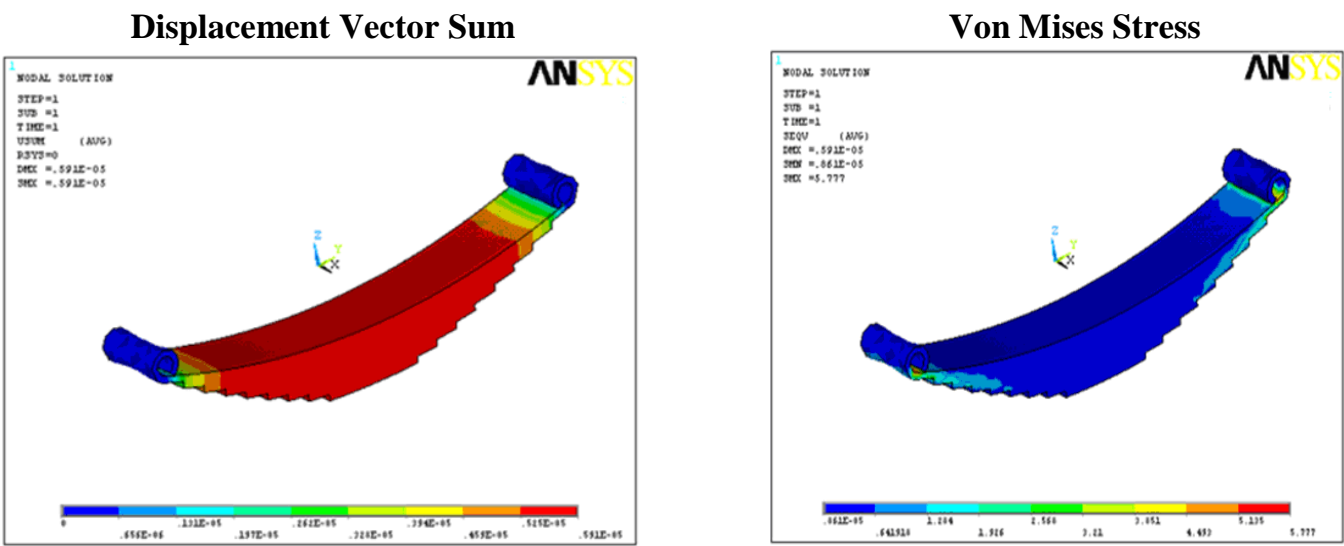

Element Type: Solid 20 node 95

\section{S - GLASS EPOXY}

Material Properties: Youngs Modulus (EX) : $88900 \mathrm{~N} / \mathrm{mm}^{2}$

Poissons Ratio (PRXY) : 0.22

Density : $0.000002490 \mathrm{~kg} / \mathrm{mm}^{3}$

Displacement Vector Sum

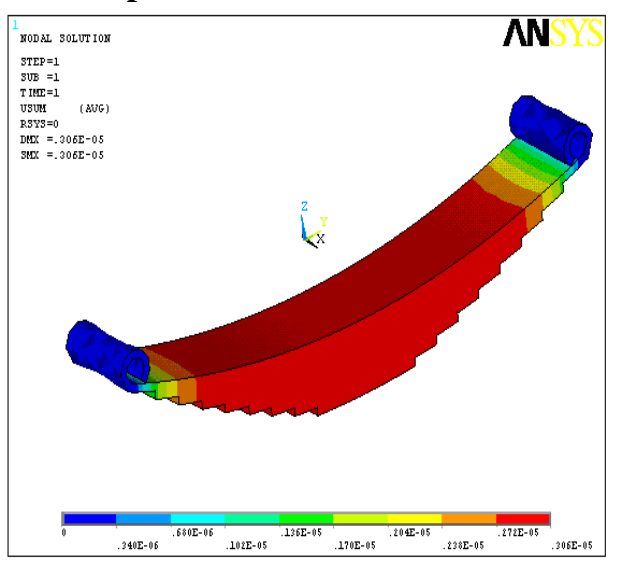

Von Mises Stress

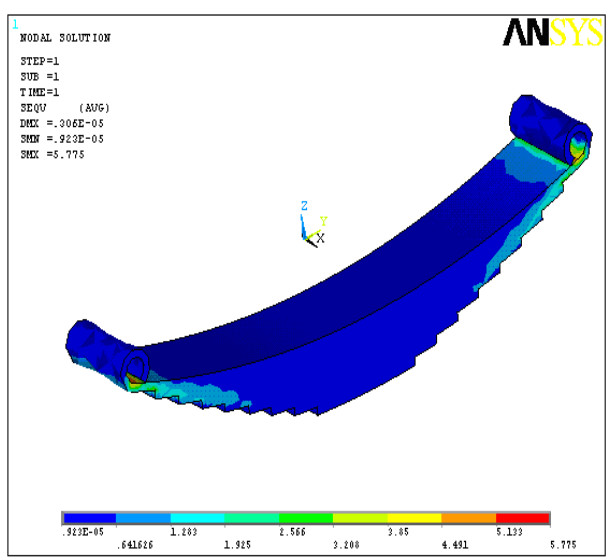

VI. Results And Discussions

\begin{tabular}{|c|c|c|c|c|c|c|c|}
\hline & \multicolumn{2}{|c|}{ ASSM } & \multicolumn{4}{|c|}{ LAYERS FOR MAIN LEAF } \\
\hline & & \multirow[t]{2}{*}{ MS } & \multirow[t]{2}{*}{ SGE } & MS & \multicolumn{3}{|c|}{ SGE } \\
\hline & & & & 1 & 1 & 3 & 5 \\
\hline & $\begin{array}{l}\text { DISP } \\
(\mathbf{m m})\end{array}$ & $0.591 e^{-05}$ & $\underset{05}{0.306} \mathrm{e}^{-}$ & 7.199 & 3.737 & 3.738 & 4.776 \\
\hline & $\begin{array}{l}\text { STRESS } \\
\left(\mathrm{N} / \mathbf{m m}^{2}\right)\end{array}$ & 5.777 & 5.775 & 589.607 & 591.554 & 714.941 & 591.554 \\
\hline \multirow{5}{*}{ MODES } & $\begin{array}{c}\text { 1. } \mathrm{Hz} \\
\mathrm{mm}\end{array}$ & $\begin{array}{l}7142 \\
6068\end{array}$ & $\begin{array}{l}20704 \\
12672\end{array}$ & $\begin{array}{c}4.618 \\
0.425203\end{array}$ & $\begin{array}{c}13.391 \\
0.888193\end{array}$ & $\begin{array}{c}13.390 \\
3.738\end{array}$ & $\begin{array}{c}11.844 \\
0.0888193\end{array}$ \\
\hline & $\begin{array}{c}2 . \mathrm{Hz} \\
\mathrm{mm}\end{array}$ & $\begin{array}{c}12553 \\
5253\end{array}$ & $\begin{array}{l}36420 \\
10974\end{array}$ & $\begin{array}{c}7.379 \\
0.589795 \\
\end{array}$ & $\begin{array}{c}21.395 \\
1.232 \\
\end{array}$ & $\begin{array}{c}21.394 \\
1.233 \\
\end{array}$ & \begin{tabular}{|l|}
18.923 \\
1.232 \\
\end{tabular} \\
\hline & $\begin{array}{c}3 . \mathrm{Hz} \\
\mathrm{mm}\end{array}$ & $\begin{array}{c}14129 \\
3830\end{array}$ & $\begin{array}{c}40983 \\
8000\end{array}$ & $\begin{array}{c}7.762 \\
0.455591 \\
\end{array}$ & $\begin{array}{c}22.493 \\
0.951639\end{array}$ & $\begin{array}{c}22.548 \\
0.950674\end{array}$ & $\begin{array}{c}19.895 \\
0.95164 \\
\end{array}$ \\
\hline & $\begin{array}{c}4 . \mathrm{Hz} \\
\mathrm{mm}\end{array}$ & $\begin{array}{c}22717 \\
6802\end{array}$ & \begin{tabular}{|l|}
65798 \\
14206
\end{tabular} & $\begin{array}{c}11.238 \\
0.468818\end{array}$ & $\begin{array}{c}32.582 \\
0.979417\end{array}$ & $\begin{array}{c}32.584 \\
0.979669\end{array}$ & $\begin{array}{c}28.818 \\
0.979417\end{array}$ \\
\hline & $\begin{array}{r}5 . \mathrm{Hz} \\
\mathrm{mm}\end{array}$ & $\begin{array}{c}33731 \\
5492\end{array}$ & $\begin{array}{l}97648 \\
11477\end{array}$ & $\begin{array}{c}15.033 \\
0.42841 \\
\end{array}$ & $\begin{array}{c}43.597 \\
0.895252\end{array}$ & $\begin{array}{c}43.583 \\
0.897543\end{array}$ & $\begin{array}{c}38.56 \\
0.895252\end{array}$ \\
\hline
\end{tabular}




\subsection{GRAPH}

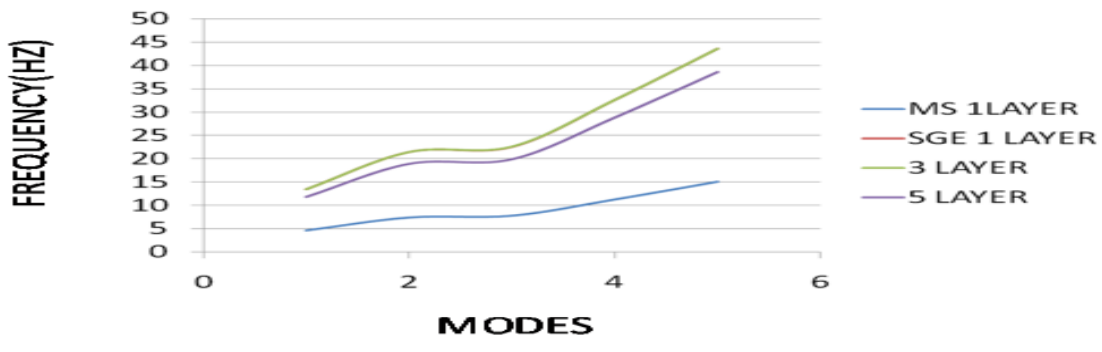

VII. Conclusion

We have done structural and modal analysis on total assembly leaf spring. The results show:

1. The stresses in the composite leaf spring are much lower than that of the steel spring.

2. The strength to weight ratio is higher for composite leaf spring than conventional steel spring with similar design.

We have also done structural and modal analysis on the master leaf for single, 3 layers and 5 layers. From the results we observed, if number of layers are increased for same thickness the vibrations are less.

In this paper we are concluding that using composite $S$ - Glass Epoxy is advantageous. The major disadvantages of composite leaf spring are the matrix material has low chipping resistance when it is subjected to poor road environments which may break some fibers in the lower portion of the spring. This may result in a loss of capability to share flexural stiffness. But this depends on the condition of the road. In normal road condition, this type of problem will not be there. Composite leaf springs made of polymer matrix composites have high strength retention on ageing at severe environments.

It is observed from the present work that the natural frequency increases, but natural frequency decreases with increase of layers. The natural frequencies of various parametric combinations are compared with the excitation frequency for different road irregularities. The values of natural frequencies and excitation frequencies are the same for both the springs as the geometric parameters of the spring are almost same except for number of leaves.

\section{References}

[1]. International Journal of Modern Engineering Research (IJMER) www.ijmer.com Vol.2, Issue.1, Jan-Feb 2012 pp-213-218 ISSN: 2249-6645

[2]. MARK'S Calculations for mechanical design by Thomas H. Brown

[3]. Machine Design by R.S. KHURMI, J.K. GUPTA

[4]. Mechanical Engineering Design by Budynas-Nisbett.

[5]. Mechanics of Solids by T.J.Prabhu.

[6]. Fundamentals of Materials Science and Engineering by William D. Callister 